


\section{Os segredos visíveis da cidade: a efemeridade da luz e da sombra na linguagem fotográfica}

RAÚL YÉPEZ COLLANTES (YEPO)

Resumo:

O presente trabalho propõe uma reflexão teórica em torno das imagens fotográficas de produção do autor, feitas entre os anos 2001 e 2006, no decorrer de específicos efeitos visuais de caráter transitório que surgem na cidade. A análise das imagens está precedida por uma revisão histórica da imagem da cidade e da obra de uma seleção de fotógrafos que incluíram a cidade dentro das suas temáticas preferidas. Adicionalmente se busca deixar explícitos alguns posicionamentos sobre a linguagem em torno do efêmero e os aspectos relacionados à imagem técnica como elemento indissolúvel da fotografia. Finalmente o estudo se debruça sobre a análise descritiva e interpretativa, de imagens que fizeram parte de três exposições temáticas do autor. 


\begin{abstract}
:
The present work proposes a theoretical reflection around the photographic images produced by the author between the years 2001 and 2006 during the passing of certain visual effects of a transitory nature that appear in the city. The analysis of images is preceded by a historical review on the image of the city and on a selection of photographers that included the city within their preferred subject matter. Add the article the intention is to be explicit on some of the positions of the language around the ephemeral and then developing aspects relating to the technical image, an unbreakable element of the photograph. Finally, the study focuses on an interpretative and descriptive analysis, the images that form part of the author's three thematic exhibitions.
\end{abstract}




\section{Introdução ${ }^{1}$}

O argumento deste trabalho começou a se constituir pouco antes da finalização do século XX, em uma atmosfera de expectativas que pretendia deixar para trás um mundo fragmentado. Com sensata ingenuidade, fiquei surpreendido de como acontecem, no cenário citadino, inúmeras mutações ao longo de um dia; a luz natural atinge completamente um por um todos os rincões da cidade e por conta da sua trajetória temporal advêm episódios únicos, não repetíveis. É como se a própria natureza desejasse patentear uma estratégia cotidiana para criar novas visualidades no mesmo espaço: outras cidades nas mesmas cidades.

Achei que ao fotografar essas faces não percebidas do panorama urbano poderia provocar no cidadão-expectador uma reação menos impassível frente à urbe e acabei organizando, com essa motivação, várias mostras de fotografia. Durante um período de já quase uma década, o tema tornou-se recorrente em minha produção, a ponto de encontrar na linguagem do efêmero uma nova forma de conceber a cidade. Foi através dessa experiência que pude reflexionar sobre o papel decisivo das cidades na história das civilizações e em como seu desenvolvimento sociocultural se modifica em função do dinamismo dos grandes conglomerados urbanos. Comprovei também que, infelizmente, na atualidade, devido aos vários convencionalismos estabelecidos pela mecânica capitalista, a maioria de nós não tomou consciência do entorno construído; percorremos ruas e calçadas das nossas próprias urbes na qualidade de visitadores desentendidos e distantes. Tentarei, assim, revelar uma cidade "oculta" através deste trabalho, mostrar que ela convive conosco, ainda que flutuando no mundo do impalpável.

Na construção fictícia destas "cidades paralelas", certos lugares, mesmo que visíveis o dia todo, "aparecem" aos olhos vorazes do artista unicamente em brevíssimos momentos. Cada componente do mobiliário urbano ou detalhe arquitetônico normalmente despercebido pelo habitante comum se transforma em um potencial referente imagético que adquire vida própria, sai do anonimato e surge com eloquência pela invasiva e passageira incidência da luz sobre ele em uma exata fração de segundo. Nesse caso, os elementos urbanos convertidos em "motivo" aparecem à vista, fazem um chamado de alerta, emergem de um efeito provisório e ultrapassam o filtro subjetivo/mediador do fotógrafo para serem capturados e concretizados no ato fotográfico. Uma seleção das imagens, resultado desse processo, constitui-se no objeto de estudo da pesquisa.
1. O presente artigo está baseado no texto da dissertação de título homônimo orientada pela Prof ${ }^{\underline{a}}$ Dr - Maria Elízia Borges no curso de Pós-graduação em Cultura Visual - Mestrado da Fav/UFG. 
Com os primeiros produtos tentei organizar uma mostra já no ano de 1999. Em Quito-Equador, o cânone de valor referente ao assunto ao qual a fotografia se refere estava marcado, na época, por duas características essenciais, estabelecidas visivelmente pela prática de um fechado circulo de fotógrafos-artistas: as propostas deveriam atingir temáticas relacionadas aos conflitos sócio-políticos do país e do mundo e as fotos teriam de ser tiradas com película em preto e branco. Mas meu trabalho fugia amplamente das demandas, pois era uma proposta que explorava a fotografia abstrata, colorida e sem presença da figura humana.

No alvorecer do século XXI, a fotografia artística equatoriana se consolidou cada vez mais, as mostras de fotografia nutriram a oferta cultural da capital e se instituía o renomeado "Mês Internacional da Fotografia", organizado pelo Centro de Imagem da Aliança Francesa de Quito, a cada dois anos, no mês de outubro. Esse evento, de grande transcendência local, levou para os centros culturais da cidade obras clássicas e contemporâneas dos grandes mestres da fotografia mundial. Entre um e outro acontecimento, as ideologias dos curadores mudaram a ponto de dar espaço às novas expressões, e as galerias do circuito artístico nacional recebiam propostas fotográficas com mais frequência. Nessas circunstancias inteligíveis encontrei o momento oportuno para empreender o meu grande desafio: desvendar, através da fotografia, os segredos visíveis da cidade.

Dado que o trabalho integra a poética com a história, teoria e crítica da imagem, julguei adequado estruturar a pesquisa partindo previamente de um quadro teórico que possibilite estabelecer fundamentos conceituais na construção das imagens. Com esse objetivo, começo fazendo uma revisão histórica sobre, a imagem da cidade e a fotografia das paisagens urbanas. Além disso, penso ser importante meditar sobre a relação arte-cidade e destacar a obra de um selecionado grupo de fotógrafos-artistas que incluíram as paisagens urbanas dentro das suas temáticas preferidas.

\section{A imagem da cidade e a fotografia das paisagens urbanas}

O título envolve a cidade, é o cenário de onde se extrai o produto deste trabalho, uma unidade complexa de práticas e representações sociais organizadas e idealizadas sob uma multiplicidade de fatores. No trabalho de campo constatei certa miopia cultural e social em relação à visualidade urbana, por isso vale perguntar: Qual é a postura do habitante da cidade em todo esse complexo 
mundo de manifestações visuais? Acontece que hoje em dia, em pleno século XXI, a dinâmica das metrópoles engendra um homem quase mecanizado, com ideais materialistas e cada vez mais afastado da percepção estética da cidade e dos valores culturais e sociais. Muitos seres humanos moram em grandes concentrações urbanas, a paisagem artificial de ruas, edifícios e mobiliário urbano faz parte do dia a dia do cidadão, mas apesar disso eles ignoram seu entorno.

Posso dizer que, de alguma forma, as exposições de fotografia que são parte da proposta foram organizadas para permitir ao cidadão uma reflexão do seu papel frente à urbe; tentei sempre provocar uma sensibilização que rompa a apatia gerada finalmente pela rotina cotidiana da mesma cidade. Concordo plenamente com Sandra Makowiecky ${ }^{2}$ em que quando a cidade é nosso objeto de estudo pouco importa se somos pesquisadores ou mesmo simples moradores da cidade, o fato é que devemos perceber que ela nos pertence e faz parte do nosso imaginário e da nossa identidade. No transcorrer dessa dinâmica urbana caracterizada pelos contínuos câmbios, vale à pena agir, eis a necessidade da nossa proposta: revelar os segredos visíveis da cidade, aqueles efeitos de curta duração que estão ligados a ela, qual parasito precisando de hospedeira. O descobrimento não leva mais que um instante e cada aparecimento têm de ser decifrado com os códigos fugazes da linguagem do efêmero. Uma mudança sobre outra pronta a criar outra sucessiva e assim até $\mathrm{o}$ infinito. Momentos excepcionais que merecem, através da fotografia, o favor do perpétuo!

Na Europa do século XIX a industrialização dos processos construtivos e o desenvolvimento de novas técnicas de utilização do ferro originaram importantes transformações urbanas. Foi possível criar estruturas leves e resistentes, montadas e armadas em tempos relativamente curtos. Com aquela tecnologia se construíram as grandes estações de trens parisienses, a Torre Eiffel, o Palácio de Cristal, em Londres, e algumas outras importantes construções como pontes, mercados, residências e edifícios de mais de quatro andares. A profusão dos prédios converte a cidade em paisagem de arquitetura e sua configuração passa a ser apreendida pela percepção artística moderna. Simon Marchán Fiz, em seu livro Contaminaciones Figurativas, anota que nos albores do século XX:

As metrópoles são ainda jovens, sua beleza apenas tem desflorado ou começado a ser desvelada pelos pintores, mas para penetrar nela de um modo crítico é necessário aceitar que a intencionalida-
2. Em: "A iconografia urbana e os espaços cênicos da memória da cidade" 
3. Tradução realizada pelo autor do artigo. de objetiva da percepção habitual não esgota a visão como prazer e jogo nas aparências, própria da percepção estética. (MARCHÁN FIZ, 1986, p. 37) ${ }^{3}$

Tentando empreender uma nova aventura criativa, os artistas da época convivem com a cidade, exploram e experimentam a sua conexão com esses elementos iconográficos e figuras do que poderia ser considerada a manifestação do moderno. Com a espontaneidade impressionista nas pinturas da Estação de São Lázaro (1877-1897), por exemplo, Monet incorpora a dinâmica do movimento e dos acontecimentos fugazes da cidade, no marco da cobertura de ferro se evidenciam magistralmente o corpo intangível da fumaça produzida pelos trens e os reflexos da luz.

Já desde o início do século XX a pintura e a fotografia adquirem, como temática predileta, a ebulição da grande cidade. De um modo ou outro, os bairros, as praças, as ruas, os monumentos, os centros do comércio e da diversão, em conjunção com os personagens que os habitam, são representados na arte moderna com as formas sinuosas e assimétricas do art nouveau, a vibração cromática do fauvismo, a geometrização do cubismo, a representação de realidade dinâmica do futurismo e as cores fortes, contornos abruptos e densas atmosferas do orfismo e expressionismo.

Hoje em dia não poderíamos conceber a sociedade contemporânea sem sua imbricação com a cidade, por isso ela é o grande cenário da nossa pesquisa, mas também a "tela" onde o fotógrafo concebe sua própria criação, ele apreende a cidade de um jeito peculiar que somente é desvendado em cada fotografia. É graças aos fotógrafos das paisagens urbanas e a sua "visão fotográfica" que muitos habitantes redescobriram a cidade. Cada um ao seu modo conta em imagens a relação que os une, fotógrafo e cidade estão ligados por essa intimidade que nasce do contato cotidiano. Vamos conhecer a seguir a obra e o pensamento de alguns deles, suas visões fotográficas de cidade que se constituem em mais um elemento estrutural do marco teórico do presente trabalho.

Embora a arquitetura da cidade fosse alvo de importantes trabalhos no período pioneiro da fotografia, foram outros os temas que ganharam relevância na sua história. Tentando introduzir alguns elementos de análise, faremos, sobre esse tema, uma abordagem preliminar focada em exemplos específicos. Poderíamos trazer aqui mais de uma centena de fotógrafos que, sendo reconhecidos pela história da fotografia, retrataram a cidade em 
várias épocas e de diversas ópticas, mas, dado que esse não é o objetivo principal deste estudo, vamos citar apenas o trabalho de alguns deles, do qual se pode extrair certo caráter precursor.

Na lista desses nomes reconhecidos pela história da fotografia encontram-se, entre outros : Eugène Atget (França, 1857-1927), por ter realizado, de 1898 a 1925, uma grande quantidade de fotografias dos diferentes bairros de Paris. Ele foi o primeiro a representar a arquitetura da cidade com uma visão objetiva e desprovida de qualquer acontecimento, mostrando um obsessivo interesse pelos edifícios destinados a perecer na dinâmica expansão urbana.

O fotógrafo húngaro Gyula Halász, conhecido como Brassaï (18991984), foi seduzido também pela capital francesa. Ele é citado aqui por ter a permanente intenção de revelar o que está escondido no cotidiano e "fazer as pessoas verem um aspecto da vida diária como se elas tivessem descoberto isso pela primeira vez" (BRASSAÏ, 1987).

Henri Cartier-Bresson (França, 1908-2004), um dos maiores mestres da fotografia do século XX, tinha uma capacidade excepcional para capturar o momento efêmero nas ruas. Seu conceito de fotografia baseava-se no que ele chamava de 'o momento decisivo', o instante em que se evoca o espírito fundamental de alguma situação, quando todos os elementos externos estão no lugar ideal.

Alfred Stieglitz (USA 1864-1946) impulsionou, em reação ao pictorialismo, a prática da Straight Photography, que propunha a volta à fotografia pura, direta, sem manipulação alguma. Sempre disposto a explorar novas ideias visuais, deu um valor estético às sombras, fotografando, no momento certo, as figuras que elas desenham nos terraços e nas fachadas dos edifícios.

Andreas Feininger (Francia, 1906-1999), por seus recortes visuais inesperados, nos quais se incluem espetaculares cenas de Manhattan, a ponte de Brooklin, o Empire State Building, as ruas cheias de vida, paisagens abstratas da cidade e pormenores minúsculos de plantas, pedras ou esculturas.

Franco Fontana (Itália, 1933), devido ao fato de ele haver reinventado a cor como meio expressivo e criado, a partir dos anos 6o, imagens provocativas da paisagem natural e urbana. "Fontana transcreve a realidade em termos absolutamente pessoais, transfigurando-a segundo um esquema essencial de formas e luzes" (VIGANÒ, 2005). 
Martín Chambi (Peru, 1891-1973), natural da pequena vila de Coaza. Desenvolveu seu trabalho inicial em Arequipa, mas a cidade de Cuzco foi sua grande musa na maior parte de sua produção. Seu trabalho pulcro, apurado, preciso desde o ponto de vista da composição explora uma paisagem urbana de contraluzes que dão volume ao espaço e corpo à sombra.

No Equador, quem dirigiu seu olhar preferencialmente à cidade foi José Domingo Laso (Equador, 1870-1927). Em um período de onze anos, a partir de 1911, publicou cinco livros sobre Quito, sua cidade natal. Segundo se conhece, foram os primeiros livros no país, dedicados ao "novo arte da fotografia"

No Brasil a obra de Militão Augusto de Azevedo (Brasil, 1837-1905), que foi o primeiro a retratar sistematicamente a transformação urbana da cidade de São Paulo; Antônio Saggese (São Paulo, 1950), por sua extraordinária concepção do provisório, que abrange todo um universo de temporalidade, pois ele se vale de um pedaço de parede para narrar uma história visual com o vigor da textura e a força da cor. E Cássio Campos Vasconcellos (São Paulo, 1965), por ter uma visão de cidade marcada pela experimentação e pela ficção. Na obra analisada, ele apresenta um espaço urbano esquecido, carente de figuras humanas, que remete a uma dimensão intemporal de solidão e desamparo.

Os fotógrafos aqui citados são apenas uma marca visível na ampla gama de artistas que, de um modo ou de outro, focaram parte de seu trabalho na cidade. Seria possível adicionar mais uma lista de nomes que, sem serem especialistas nos temas da cidade e de suas arquiteturas, aportaram na fotografia das paisagens urbanas, mas o propósito deste trabalho é demarcar certas noções iconográficas implícitas na obra, cujo conteúdo aporta especificamente no tratamento da temática.

Nossa finalidade não é encontrar na obra desses artistas selecionados (diversos nos estilos, distantes no tempo, diferentes na expressão, mas coesos na temática da cidade) uma semelhança visual ou referencial com as fotografias do autor. Não teria sentido, pelo menos neste estudo, fazer comparações puramente físicas, apelando à analogia compositiva ou temática das fotos, mesmo que no sentido interpretativo as duas convirjam em um discurso complementar.

Após este breve percurso convém mencionar que, no tempo de investigação prática e teórica, perduraram na memória, latentes 
e silenciosas, as originais composições de Atget, as atmosferas misteriosas de Brassaï, os momentos efêmeros de Cartier-Bresson, os ousados pontos de vista de Abbott, o manejo dos planos nas monumentais paisagens urbanas de Feininger, a poética da cor de Fontana, e o jogo de luz de Chambi. Nenhum deles precisou de manipulação alguma para suscitar essas sensações no espectador, e é assim que está também construída minha proposta. Todas as imagens de os segredos visíveis da cidade são produto do respeito ao procedimento puramente fotográfico. Tento demonstrar com meu trabalho que nada supera um efeito efêmero que efetivamente aconteceu.

\section{A imagem técnica e a linguagem fotográfica em torno do efêmero}

A exceção das imagens da primeira mostra originadas a partir de película positiva de $35 \mathrm{~mm}$, todo o resto de imagens das mostras que são descritas neste trabalho foram capturadas eletronicamente. Mas essas imagens são produto da fotografia direta e livre de qualquer reconstrução virtual. Muita coisa se tem colocado no campo especulativo em torno da fotografia digital ao ponto de fazê-la responsável até mesmo, dos resultados obtidos mediante a aplicação de softwares de manipulação pós-produção de imagens. No que faz relação à linguagem fotográfica, sua técnica primordial, os princípios aplicados da óptica, a mecânica incorporada, os critérios de composição e até seus usos e funções, seguem tão vigentes quanto antes. $\mathrm{O}$ que tem mudado na verdade, está mais no terreno da tecnologia de captação da imagem no corpo da câmera, a substituição da película de emulsão de halóides de prata por um sensor eletrônico de luz, chamado de CCD (ChargeCoupled Device) ou "sensor de imagem", responsável de converter os sinais luminosos em códigos binários que são logo processados digitalmente e armazenados em um cartão de memória, em definitiva, uma inevitável evolução à que não podia escapar o aparelho fotográfico na atualidade. No campo subjetivo embora, pode acontecer que no processo de transição quem trabalhou a maior parte de sua vida com o sistema analógico possivelmente sinta falta da conexão física e perceptiva com o filme na hora do disparo, mas com certeza os acréscimos tecnológicos irão compensar em pouco tempo qualquer arrebato de nostalgia.

A linguagem da fotografia digital incorpora conseqüentemente, além dos elementos técnicos relacionados com a óptica, a mecânica e a composição, o processo de digitalização que vai sendo aperfeiço- 
ado cada dia. Esses elementos vão intervir decisivamente na interpretação e construção de sentidos na fotografia contemporânea.

O tema do efêmero não pretende alcançar, em meu trabalho, níveis filosóficos, mas convida o espectador, por meio da experiência visual, a surpreender-se ante o fato natural de que tudo muda a cada hora do dia, gerando atmosferas diferentes no mesmo espaço. Essa dinâmica, explorada já pelos impressionistas, encontra na linguagem fotográfica um meio de conseguir, em frações de segundo, com que todos esses momentos fugazes se prolonguem no papel fotográfico ou na tela do computador para serem objetos de apreensão e contemplação.

No transcorrer deste projeto sempre quis descobrir porque os potenciais motivos fotográficos apareciam no meu olhar unicamente em determinados instantes e sumiam logo para não voltar jamais. Um dia eu decidi prestar atenção, fui com minha câmera para as ruas e tentei segurar cada oportunidade, mas nada aconteceu. Após longas convivências com as luzes que incidem nas paisagens urbanas, entendi que o processo de busca não é unilateral, o fotógrafo encontra os motivos apenas quando eles aparecem ao fotógrafo. É como se assistíssemos a um momento privilegiado através do qual podemos nos conectar com sua "aura", descobrir o ponto onde convergem todos os seus atributos que nos são entregues por um instante para volvê-lo imagem. Essa é uma oportunidade impossível de perder e para isso devemos estar preparados.

Buscando justamente uma percepção menos habitual do cenário citadino é que certos dias, acompanhado da minha câmera, vejo na rua o mundo acordar reluzente muito cedo na manhã. A luz do Sol cobre as cidades, mostrando objetos escondidos, rincões esquecidos, detalhes imperceptíveis. O aparecimento dura o exato instante de um pestanejo, esse é o tempo do efêmero, uma partícula da origem que deixa tudo pronto para sumir. Fugaz por vocação, o efêmero é sempre passageiro, a única verdade intangível, o mimetismo do presente, a substância do passado.

As exposições de fotografias que descreverei recolhem imagens captadas por períodos obsessivamente esgotados nesse processo, fotos que mostram projeções de sombras, objetos refletidos, naturezas brotadas, materiais reutilizados, deteriorações temporais e incidências atmosféricas, todas elas descobertas sob a é gide do efêmero e estruturadas em dois grandes eixos: o valor estético do cotidiano; $\mathrm{e}$ 
os mundos paralelos nas paisagens urbanas. Na base desses enunciados foi conceituada a produção autoral que veremos logo.

O procedimento adotado para a análise das imagens de produção do autor contempla duas ópticas diferenciadas, mas complementares: uma análise descritiva (reconstrução dos elementos da imagem) que contempla aspectos históricos, anedóticos, técnicos e classificatórios e uma análise interpretativa, (nível superior de abstração e generalização) na qual se consideram aspectos iconográficos, estéticos e conceituais. Dentro dos elementos históricos eanedóticos, os lugares onde foram captadas as imagens são referências concludentes na análise descritiva. A outra parte explica os elementos técnicos partindo do mesmo processo de conformação da imagem técnica, as considerações compositivas e todos os fatores ligados à técnica.

Em relação aos aspectos estéticos e conceituais, a análise tende a convergir com as práticas artísticas contemporâneas que, segundo David Green, tem se convertido em um território de importância crescente. Ele afirma que "em resposta a essas práticas as perguntas que fazemos sobre fotografia tem se deslocado das formas semióticas de análise cultural ao terreno da estética e a fenomenologia" (GREEN, 2007, p. 27, tradução do autor). Em concordância com essas novas tendências, analisamos os aspectos da estética na sua especificidade fotográfica, que dá "acesso a um modo inédito de ver a realidade" (AUMONT, 1993, p. 307) que permite ver uma realidade interpretada. Já os aspectos conceituais dizem respeito à construção de sentido, na qual intervém o fenômeno em si (reflexo, sombra) como elemento partícipe de um discurso, uma mensagem, um processo de representação.

\section{Eixos conceituais, exposições e análise das imagens do autor}

No eixo conceitual o valor estético do cotidiano se coloca a primeira exposição de fotografia de produção do autor que avaliaremos: A outra paisagem. Trata-se da incorporação na estética fotográfica de motivos simples, anódinos e comuns do cotidiano urbano.

A outra paisagem . Foi apresentada no Centro Cultural PUCE, no marco do VI Mês Internacional da Fotografia, em Quito, no ano de 2001, composta por trinta imagens abstratas e figurativas de vários lugares do Equador, que revelaram o valor estético do cotidiano. A obra, impressa em diferentes tamanhos com técnica digital a partir de película positiva de $35 \mathrm{~mm}$, mostra que tudo pode ser motivo 
de uma composição fotográfica, desde que a descoberta fortifique o conceito: as madeiras de reciclagem para fechar um terreno, o segmento de uma calçada, o muro de um estacionamento ou um poste da luminária pública... Curada por Camilo Luzuriaga, reconhecido crítico e cineasta equatoriano, A outra paisagem "trata-se de uma provocação [...] já que suas 'paisagens' são o resultado de um deliberado e obsessivo olhar que busca inverter o passo da consciência visual" (LUZURIAGA, 2003, p. 1, tradução do autor). É uma paisagem urbana, ou às vezes rural, marcada pela mão ou pelo pé do homem, sua intervenção agressiva, seu desrespeito pela natureza pura ou construída, a falta de conexão com a terra...

A obra abrangeu imagens da natureza rural e construída, desde a vegetação de altitude até os muros, ruas e calçadas de cidades serranas e litorâneas. A ideia, por um lado, foi refletir sobre a prodigalidade da natureza, que só precisa de um pouco de garoa e algo de poeira para sobreviver nas grandes cidades e, por outro, evidenciar como os objetos produzidos pelo homem e convertidos em material descartado ou lixo formam parte da outra paisagem das urbes.

O Curador destaca duas condições do autor que resultam verdadeiras: a intencionalidade de inverter a percepção habitual sobre a fotografia de paisagens e a preocupação de injetar sempre uma dose de estética nas imagens. Porém, a proposta tentava uma visão diferenciada: utilizar o lixo ou material descartado de diversas índoles para construir uma proposta estética através da fotografia direta, técnica que lida com uma acessibilidade limitada aos motivos e exige observação e 'busca' constante, além de horários específicos, condições patéticas de iluminação, cuidados compositivos e captura em momentos essencialmente efêmeros.

O grande cenário dessa produção é Quito, capital do Equador, onde foi tirada boa parte das fotos que integraram essa mostra. Cercada, do lado ocidental, pelo vulcão Pichincha, ainda ativo, e do lado oriental pelo rio Tahuando, Quito é a segunda capital mais elevada do mundo, se extendendo ao longo de 40 quilômetros sobre uma geografia acidentada a 2.850 metros acima do nível do mar.

A luz é minha guia, por isso vou ao seu encontro nas primeiras horas do dia e assisto a cada segundo do ocaso. "Escrever com luz" significa valer-se do intangível para expressar ideias em uma fração de segundo. São os momentos em que os objetos urbanos cobram vida, se revelam ao meu cérebro, pedindo para 
serem fotografados. No meu trabalho procuro limpeza, equilíbrio, impacto visual, eu tenho muita atração pelo enquadramento geométrico seguramente herdado da minha formação como arquiteto. Raramente uso distâncias focais extremas, com uma objetiva normal consigo mostrar a essência dos motivos.

Analisando a modo de exemplo, apenas uma das fotos da mostra, posso afirmar que, como explorador dos cantos mais comuns da cidade, nunca tive certeza absoluta do significado que a rua representa para cada cidadão, nem percebi a sua relação com os equipamentos habitualmente ignorados do mobiliário urbano. Quis então experimentar a reação dele frente a objetos que compartem o cotidiano de quem caminha pelas ruas e achei interessante fotografar um poste de iluminação. Não encontro elemento mais agressivo e contaminante visualmente do que essas enormes estacas prendidas ao chão para apoiar cabos de eletricidade, telefônicos ou fios eletrônicos. Eles se erguem arrogantes, produzindo uma vista repetitiva e redundante, estão ali impostos pela necessidade, no entanto, não parecem incomodar ninguém e até passam despercebidos para muita gente. Acontece que, de acordo com Michel de Certeau (1994, p. 171):

Tudo se passa como se uma espécie de cegueira caracterizasse as práticas organizadoras da cidade habitada. As redes dessas escrituras avançando e entrecruzando-se compõem uma história múltipla, sem autor nem espectador, formada em fragmentos de trajetórias e em alterações de espaços: com relação às representações, ela permanece cotidianamente, indefinidamente, outra.

Especialmente no setor norte de Quito se constata que "a cidade-panorama é um simulacro 'teórico' (ou seja, visual), em suma, um quadro que tem como condição de possibilidade um esquecimento e um desconhecimento das práticas" (CERTEAU, 1994, p. 171). Estimulado pela ideia, fui trás de meu objeto, descobrindo mais um mundo submerso da cidade: eram tantos postes distribuídos na selva de cimento que novamente tive que decantar as múltiplas possibilidades. Usando sempre como princípio a fotografia direta, tentei encontrar o momento preciso de luminosidade, as qualidades cromáticas, as manifestações de deterioração, as anomalias e aditamentos ornamentais que um poste poderia oferecer até obter minha fotografia (Figura o1). Quando estamos à procura de motivos que possam transformar nossas ideias em imagem, dirigimos a atenção a elemento específico, mas como já disse, na exata hora de escolher o objeto 
Figura o1

Raúl Yépez Collantes [YEPO]

Quito, fevereiro 2001.

Da série "A outra paisagem".

Fonte: www.yepo-photo.com para "bater" a foto, por alguma causa indecifrável é o objeto que escolhe você, tem sempre um deles que embrulha seu cérebro de sedução e fantasia. A conexão acontece em um ato repentino, como se uma força invisível absorvesse o seu corpo em direção a ele e um feitiço se apoderasse do olho e apontasse a cena.
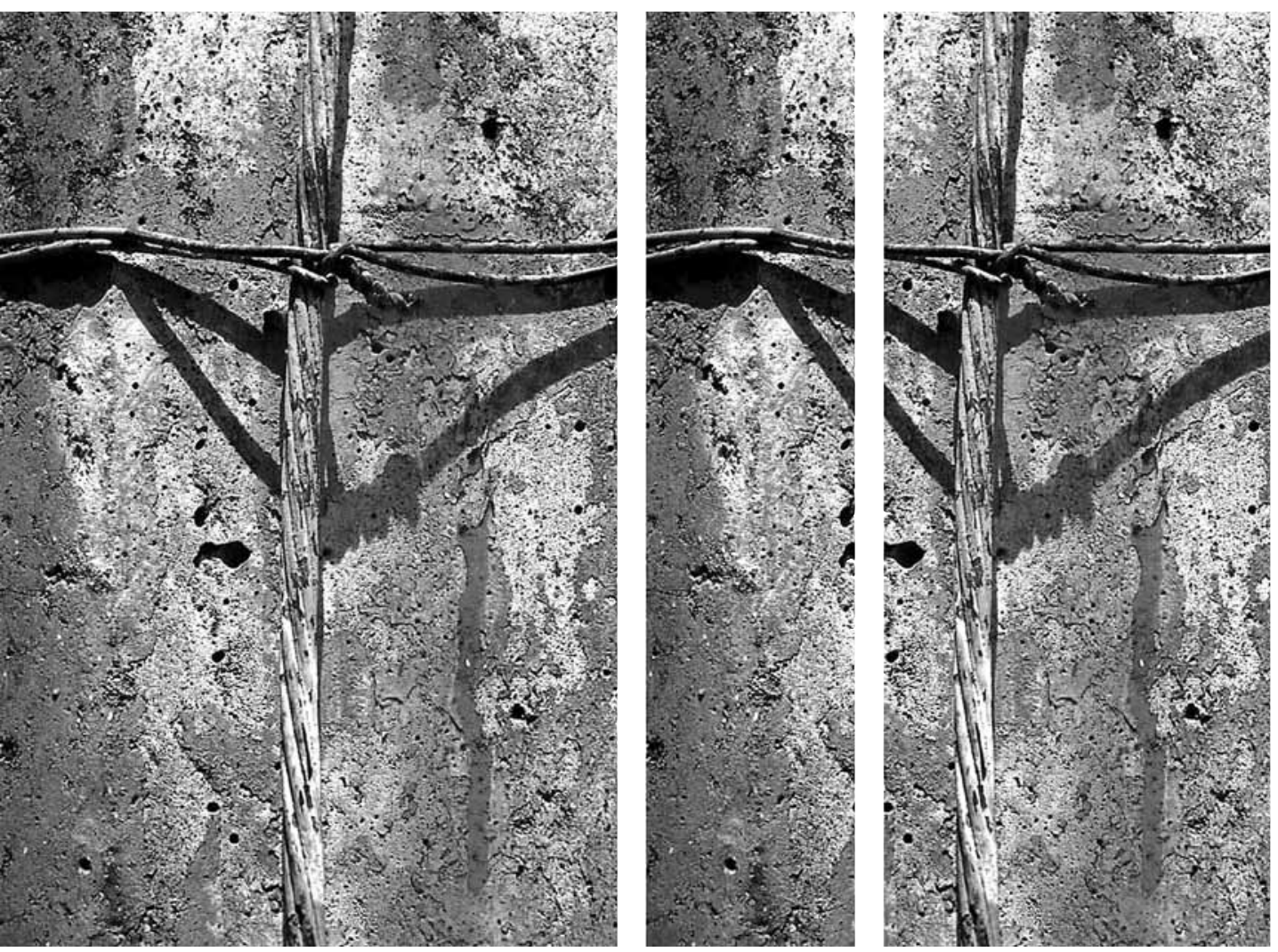

Com o dedo apoiado no disparador da câmera, elegi o formato vertical para acrescentar a natureza do poste e tirei a foto. Pode-se ver, em primeiro plano, a presença de um cabo de arame fixado perpendicularmente por fios de menor espessura, estes últimos permanecem em posição horizontal, originando uma sombra dura. Pela figura que essa sombra descreve ao redor da superfície cilíndrica dá para imaginar que um dos fios está ligeiramente afastado do arame, introduzindo um efeito de terceira dimensão e profundidade à imagem. O fundo revela as qualidades de algumas tintas, resquício de algum grafite ou propaganda 
política temporária em visível processo de deterioração, atuando como uma tela de rica trama e cálida sensação cromática devido à gama de matizes amarelas, laranja e vermelho. A marca do tempo apagou parcialmente as tintas, deixando bordas acidentadas, mistura de cores e inúmeras porosidades de vários diâmetros que imprimem dramáticas texturas.

A intersecção dos arames arranjados no terço superior do enquadramento, somado à sombra que produzem, lembra o símbolo da cruz latina, e se incluísse ainda os comentários de alguns visitantes mais imaginativos, até descobriríamos a alegoria de um homem crucificado como representação do homem oprimido pela metrópole. O que obtive finalmente, no meu juízo, foi uma imagem enigmática. Se eu não explicasse ninguém saberia o que é, já que dificilmente percebe-se uma analogia com seu referente. Esperase que o matiz cinza do cimento seja o vestígio mais perto do objeto real, mas isso é relativo, o indício carece de contundência. Mas deu resultado, à noite da inauguração todo mundo, depois de ficar sabendo o que tinha sido fotografado, expressava que desse dia em diante olharia com mais cuidado os postes da cidade.

Todavia, resta mais um pormenor que o leitor com certeza terá percebido: três cortes da mesma imagem juntos um do lado do outro. $\mathrm{O}$ tamanho da impressão digital a partir de diapositivo de $35 \mathrm{~mm}$ exposta ao público era de $100 \mathrm{x} 70 \mathrm{~cm}$, ou seja, uma fotografia de grande formato. Usando esse tamanho, posso mostrar cada uma das bondades estéticas da imagem com grande detalhe, então percebi que eram tantas as opções de contemplação que decidi induzir o expectador sob duas hipóteses visuais. Dividir a imagem permite, por um lado, a possibilidade de advertir detalhes que não foram enxergados na visão geral da unidade e, por outro, me dava a oportunidade de representar a fragmentação como uma das principais características da sociedade urbana na finalização do século XX.

O ícone do homem moderno pode ser representado, hoje, pelo transeunte apressado, que não tem tempo de deter-se a observar. Enquanto artista pesquisador do campo da fotografia, eu tento chamar a atenção para partes do cotidiano da cidade que são invisíveis para o indivíduo urbano. Há milhares de homens cegos circulando pelas ruas com os olhos saudáveis!

No eixo conceitual os mundos paralelos nas paisagens urbanas estão colocadas as outras duas exposições de fotografia de produção 
4. Nesse ano a UNESCO, pela primeira vez na história, determina como Patrimônio Mundial 7 sítios na Europa, 3 na África e unicamente 2 em América Latina. Estes últimos correspondem à cidade de Quito e às Ilhas Galápagos, os dois no Equador (site da UNESCO: http://portal. unesco.org). do autor: A memória dos charcos e Sombras nada más. Trata-se de efeitos visuais que criam uma percepção diferente da cidade.

A memória dos charcos. Apresentada também no Centro Cultural da PUCE foi selecionada para representar o Equador no VIII Mês Internacional da Fotografia, em Quito, no mês de outubro do ano 2005. São quarenta e cinco obras que representam um olhar diferenciado da cidade antiga, um bocado de luz submergido nas poças de água no chão das praças, ruas e calçadas do Centro Histórico de Quito.

Essa cidade, tal um livro aberto que têm de se decodificar através das imagens apresentadas pelo fotógrafo, reflexos cristalinos construídos por pedra e água, terra e madeira, cornijas e balcões, céus azuis e nuvens efêmeras. Reflexos que se desenham entre planos que se superpõem e matizam.

(MOYA, Rómulo, 2005, p.3, tradução do autor)

No conjunto se observam detalhes dos edifícios patrimoniais, quase sempre despercebidos pelo transeunte comum. Porções de água detida como por encanto nos buracos do solo que revelam uma textura visual, uma imagem tão efêmera como o momento mesmo. Um efeito da natureza criada unicamente para ser olhado, como o pôr do Sol ou o arco-íris... Uma imagem cheia de fragilidade, que pode desaparecer com somente a incidência de um vento intruso ou de uma vassoura desentendida.

O Centro Histórico de Quito é um verdadeiro museu a céu aberto de 320 hectares, assentado em uma geografia irregular que sobe colinas, desce vales e rodeia fendas naturais. Nele se guardam autênticas jóias arquitetônicas, antigas tradições, ricas lendas e rincões emblemáticos. Devido a essas características, a cidade é considerada "Relicário da Arte em América" e foi a primeira latino-americana no mundo em se fazer credora do título de "Patrimônio Cultural da Humanidade" no ano de $1978^{4}$. Rodeada por vulcões ativos, no meio da majestosa Cordilheira dos Andes e distante $22 \mathrm{~km}$ da linha equinocial, no meio do mundo, essa zona ostenta excelentes condições de preservação, várias obras de grande valor artístico e uma história mais antiga que a de suas próprias edificações (Figura 02).

É assim o mágico cenário de onde foi extraída A memória dos Charcos, uma verdadeira exploração de poças de água insignificantes, que ganharam presença e destaque nessa exposição 
do ano de 2005. O reflexo então tem papel protagonista na proposta. Eu fascinei-me com o reflexo desde que descobri a dupla imagem do céu e das montanhas nas lagoas repousadas dos Andes e nos troços de pedra umedecidos. Não o entendi na sua verdadeira dimensão até que decidi fotografá-lo. Em ternos concretos, o reflexo não é outra coisa que uma construção ficcional, um efeito governado pela luz que precisa de certas condições para ser percebido.

Que sentido tem a foto de uma imagem refletida em uma poça de água no chão? Aparte de ser a fotografia o meio pelo qual o autor visa estabelecer sua relação com o mundo, o efeito em si simboliza o encanto do fugaz, o mistério do ilusório; como na 'Tamara' de Calvino (1990, p. 17): "os olhos não vêem coisas mas figuras de coisas que significam outras coisas". Há nele planejada uma turnê de probabilidades, de incertezas, aparecimentos e desaparecimentos; uma lição da efemeridade da vida nos afixando no presente. A relação icônica com os monumentos arquitetônicos patrimoniais de Quito nos assinala um recorte da
Figura 02

Raúl Yépez Collantes [YEPO]

Vista do Centro Histórico de Quito.

Fonte: arquivo pessoal, 2006

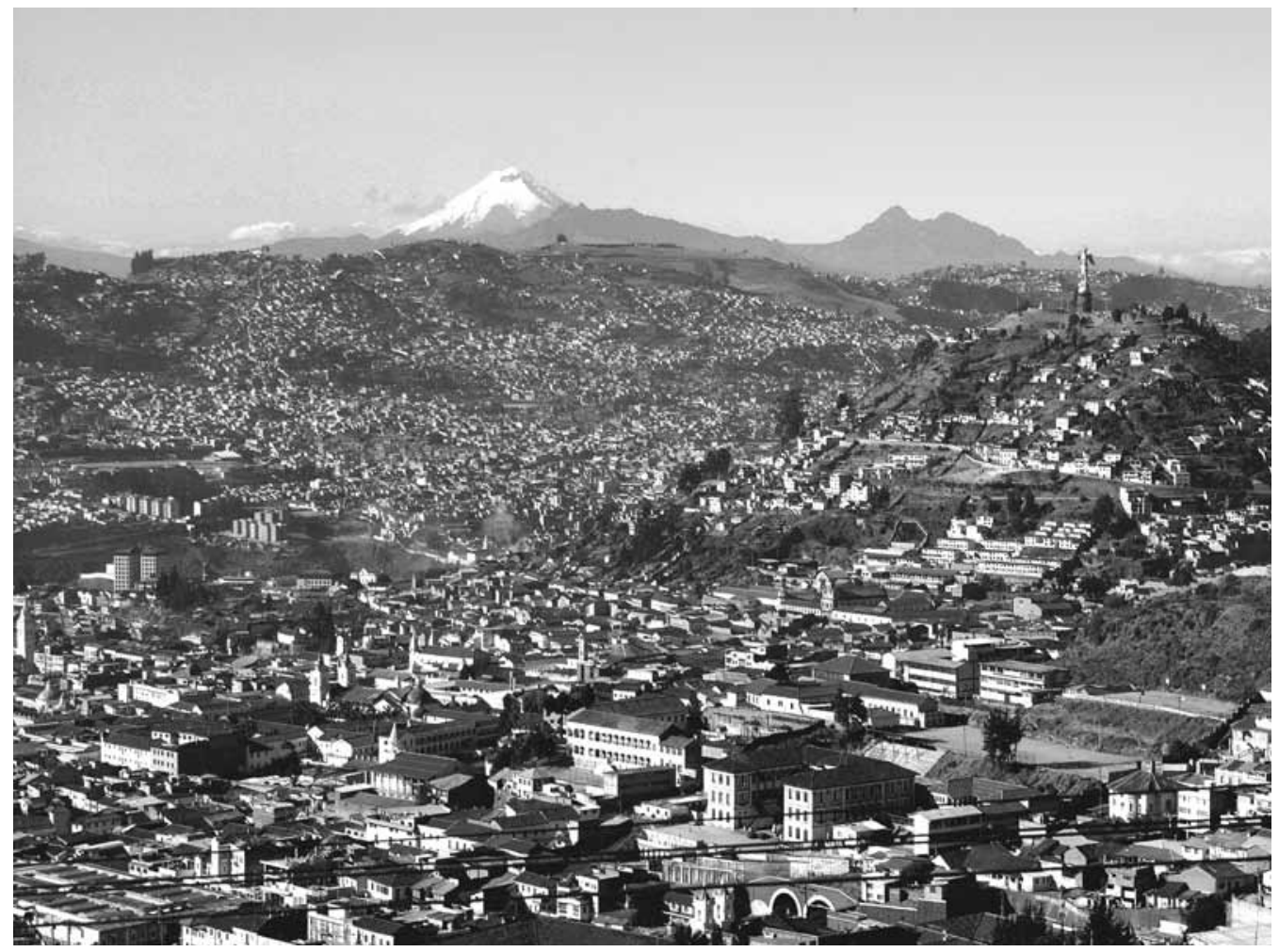


história, um vestígio da herança, a magnificência da arquitetura colonial, a riqueza ornamental dos detalhes, a finura dos artistas, a destreza dos artesãos. A coletânea exposta insinua brote recorrente do efeito na paisagem urbana, a existência de uma cidade repetida em fragmentos que convive com o todo como se se tratara de outra cidade vivendo paralelamente com sua origem. "Deste modo, o viajante ao chegar depara-se com duas cidades: uma perpendicular sobre o lago e a outra refletida de cabeça para baixo" (CALVINO, 1990, p. 53).

Na construção da imagem fotográfica os edifícios históricos parecem estar presos em uma visão fornecida por suportes: a foto sustenta os limites do contexto estabelecidos ao arbítrio do fotógrafo, o piso sustenta o charco delimitado pelas irregularidades e concavidades do chão, o charco sustenta o reflexo, e este o edifício espelhado e fragmentado. Essa cadeia de escoras afiança o tecido imagético da memória dos charcos.

Contemplando as imagens refletidas nos charcos o cidadão é induzido a exercer uma leitura diferenciada da sua cidade; nesse processo aspira-se com legitimidade que ele possa se aproximar mais dela, valorizá-la e protegê-la. Ao menos até hoje a esperança permanece intacta, como cada imagem na memória visual e na memória eletrônica. Valer-se do efêmero para apostar no permanente representa todo um desafio, mas sempre temos um caminho pela frente, um percurso a cumprir na chegada e na partida. Essa é a sensação que tenho quando observo a fotografia que intitulei de "Praça Maior" (Figura 03), um nome dado popularmente ao lugar onde foi tirada a foto. A propósito de títulos, devo admitir que eu sempre tive resistência para colocar nas minhas fotografias um nome mais 'poético', porque não quero incidir de maneira alguma na recepção inicial do espectador e, consequentemente, em sua interpretação, antepondo a minha. Prefiro colocar algo genérico e imparcial, para deixar o leitor à vontade, pois penso que desse jeito a relação dele com a foto suscita mais expectativa. Porém, relendo essa imagem, uma das minhas preferidas, até creio que merecia um título inspirador, um bocado de eloquência que patenteasse minha emoção.

A foto está estruturada em três planos bem definidos, cada um dos quais mantém com o outro uma relação cromática uniforme pela coloração cinza-azulejado da pedra que ocupa por inteiro a superfície da praça. O primeiro plano corta a plataforma arredondada do pórtico de acesso à Catedral que, sendo parte do espaço defeso, situado na frente da igreja e chamado de "átrio", fica elevado 2 metros 
acima do nível da praça. Nesse plano aparece, atravessando ao longo da parte inferior do quadro, o reflexo das balaustradas cimeiras do "Palácio Presidencial", um prédio do começo do século XIX que foi reconstruído sobre o solar onde operou o governo da Real Audiência de Quito e que hoje também é sede do governo nacional e residência presidencial.

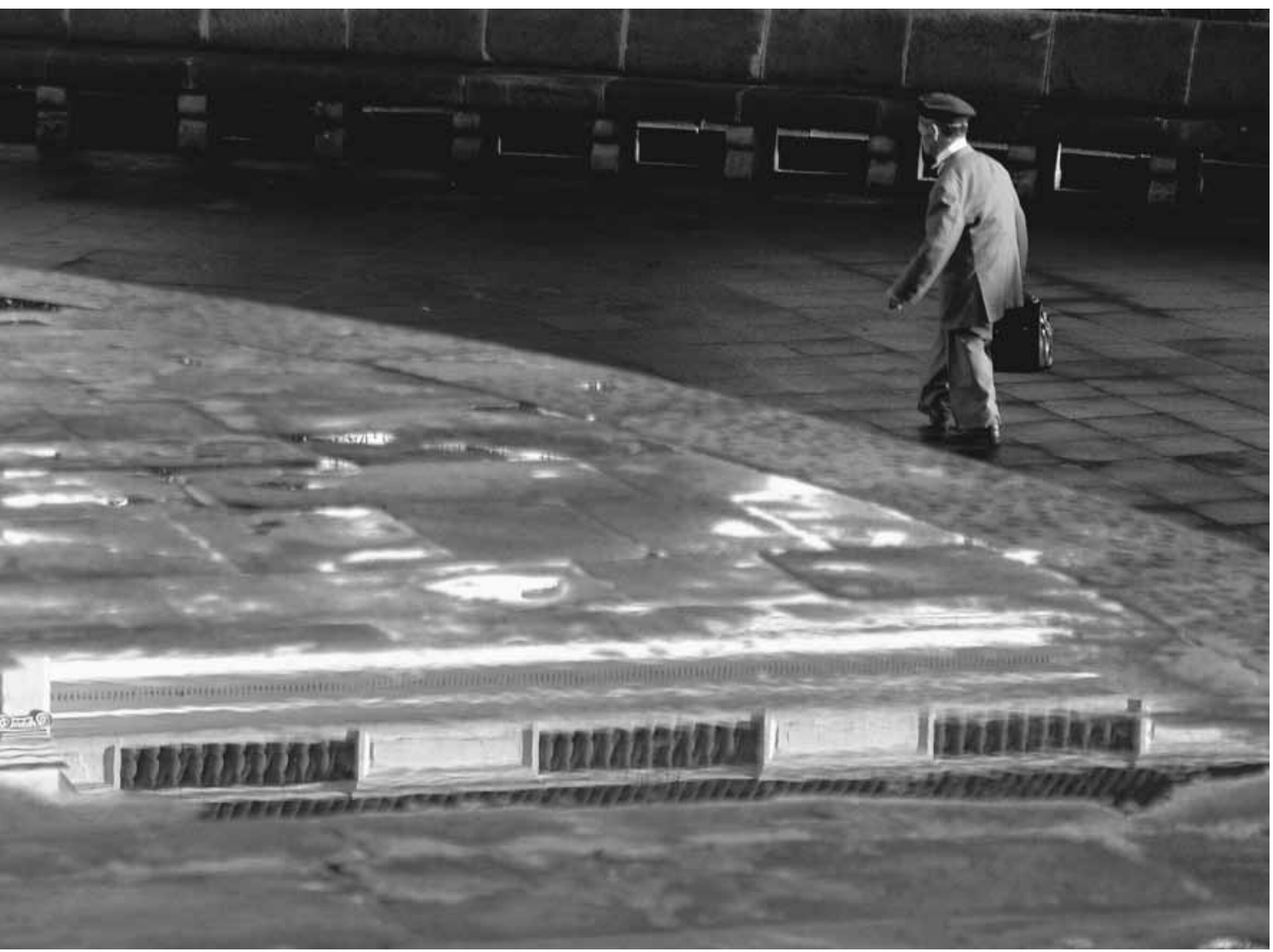

Nesse nível, estão retidas entre as concavidades das pedras mais umas pequenas poças de água, que reluzem dentro da atmosfera cinzenta da foto. Essas formas brilhantes acompanham à Figura 03

Raúl Yépez Collantes [YEPO] Quito, Praça Maior

Fonte: www.yepo-photo.com poça maior, onde a imagem refletida mostra-se um tanto tremida por causa de um vento sutil que atinge a água na hora de tirar a foto, o efeito ondulatório, além da vizinhança das outras poças, ratificam o realismo da cena.

No plano do meio vemos um idoso vestido de terno e chapéu tipo boina carregando uma mala, ele é um conhecido persona- 
gem singular e misterioso que aparece caminhando no Centro todos os fins de semana. Está contornando a escada circular ao nível da praça sobre um piso de pedra claramente mais novo, polido e regular, que com certeza foi instalado no último restauro. Sendo o único ser humano dentro do enquadramento e vestindo uma roupa do mesmo tom da pedra, parece estar imbricado na paisagem. No plano de fundo, percorre pela parte superior um banco comprido de pedra talhada com estrutura modular e base alternada entre cheios decorados e vazios. Juntados todos esses planos, notamos que há na composição uma profusão de linhas oblíquas, verticais, horizontais e curvas, cada uma delas expressa a seu modo um recorrido dentro do enquadramento. Nelas encontramos uma linguagem direta, decidida e convincente, que propicia encontros diversos em uma mesma superfície e organiza os elementos que conformam a imagem, dando-lhes sentido.

Tecnicamente podemos dizer que o espectador visualiza dois centros de interesse que convivem no quadro em diálogo permanente: o reflexo na poça das balaustradas do Palácio e o transeunte que atravessa a praça mais abaixo. Tanto o sutil tremor da água quanto o passo do personagem foram 'congelados' por ter ajustado na câmera um curto tempo de obturação. $\mathrm{O}$ efeito funciona bem na transmissão do sentido simbólico do efêmero, tudo convergindo no momento exato, no ambiente preciso, para reconstruir uma cidade de ilusão.

Enfim, as imagens contidas nos charcos pertencem ao mundo do imprevisível, do impalpável, do passageiro, mas não deixam de acontecer, estão ali para provar a coexistência de cidades paralelas extraídas das mesmas entranhas do solo urbano com a força do olhar avisado e a implacabilidade da câmera fotográfica. Aspiramos ter acertado na escolha das fotos, elas contribuem para a construção do discurso e ilustram o argumento.

No percurso da minha pesquisa sobre os efeitos efêmeros da luz sobre a paisagem urbana, além dos reflexos na água empoçada encontrei também, como resultado das continuas visitas ao Centro Histórico de Quito, outra atraente expressão estética que achei interessante explorar, é o caso das sombras, que se constituem no motivo da próxima e última exposição que analisaremos.

Sombras nada más. Foi lançada virtualmente no site www.yepophoto.com no ano 2006. Destaca-se, com 18 imagens digitais o 
mobiliário urbano dos monumentos históricos de Quito. No labirinto entre o possível e o efêmero, as sombras nascem de elementos fixos, antigos, esquecidos e inertes, mas elas os tornam ativos por que mudam, caminham, se alongam ou encolhem ao capricho do movimento do sol. São projeções de linhas ou planos que se adaptam fielmente às superfícies e adotam seu contorno, se juntando em perfeita harmonia, formas que submissas à sua origem a descrevem e enfatizam. São infinitas, diferentes, solidárias com a ação mediadora da luz natural ou artificial que incide na cidade a cada hora do dia. Uma variação do reflexo que, embora seja visível, não pode ser tocado. As sombras estão aí e muitas vezes não as vemos, convivem conosco, mas quase sempre as ignoramos.

Como em tudo o que concerne à fotografia o ponto de partida radica na luz, nesse caso, curiosamente, nosso centro de interesse carece de luz, poderíamos dizer que é precisamente seu antagonismo e por essa mesma razão o sentido muda radicalmente. Na maioria dos casos fotografamos objetos que refletem luz, fazemos uma medição dessa luz refletida e ajustamos a câmera à temperatura da luz incidente que opera sobre o objeto, mas nada disso se aplica à sombra, porque em teoria não há medida para a escuridão. Certamente uma zona escura não poderia ser percebida de forma isolada, mas sempre simultaneamente à zona iluminada, servindo esta de referência para a captação fotográfica da imagem. O que acontece, em síntese, é que se queremos representar a sombra não há mais remédio que fotografar a luz. Em termos da 'percepção da forma' podemos assumir sem rigor teórico que nesta proposta a sombra atua como figura, enquanto que a parte iluminada atua como fundo.

As imagens dessa exposição mostram que no cenário histórico do centro de Quito vários elementos de proteção, salvaguarda, fechamento, ornamento etc., que compõem o mobiliário urbano e arquitetônico, atingidos pela luz reluzente do Sol, projetam sedutoras sombras sobre diversas superfícies dos monumentos patrimoniais. As sombras projetadas sempre do lado oposto à fonte luminosa aparecem na foto como sendo linhas e planos desenhados sobre as pedras, madeiras e alvenarias dos pisos e fachadas. Essas sombras, se bem representam o objeto que as origina, nem sempre são a figura fiel desse objeto, porque elas se modificam em perfeita conjunção com as formas irregulares da superfície onde se projetam. Ou seja, o próprio objeto visualmente ausente é percebido unicamente através de sua sombra, mas 'confortavelmente' desfigurado. Em definitivo, se procura representar as coisas por meio de suas sombras. 
Na sombra deformada do objeto, participam três elementos físicos reconhecíveis: o ângulo de incidência da luz sobre ele, a disposição do próprio objeto no espaço e as formas irregulares da superfície onde se projeta. Adicionalmente, do ponto de vista estético, incide no resultado final também o ângulo de tomada selecionado pelo fotógrafo, a proximidade da câmera com o efeito e as condições de focalização, assuntos dos quais falaremos na análise da fotografia que temos escolhido:

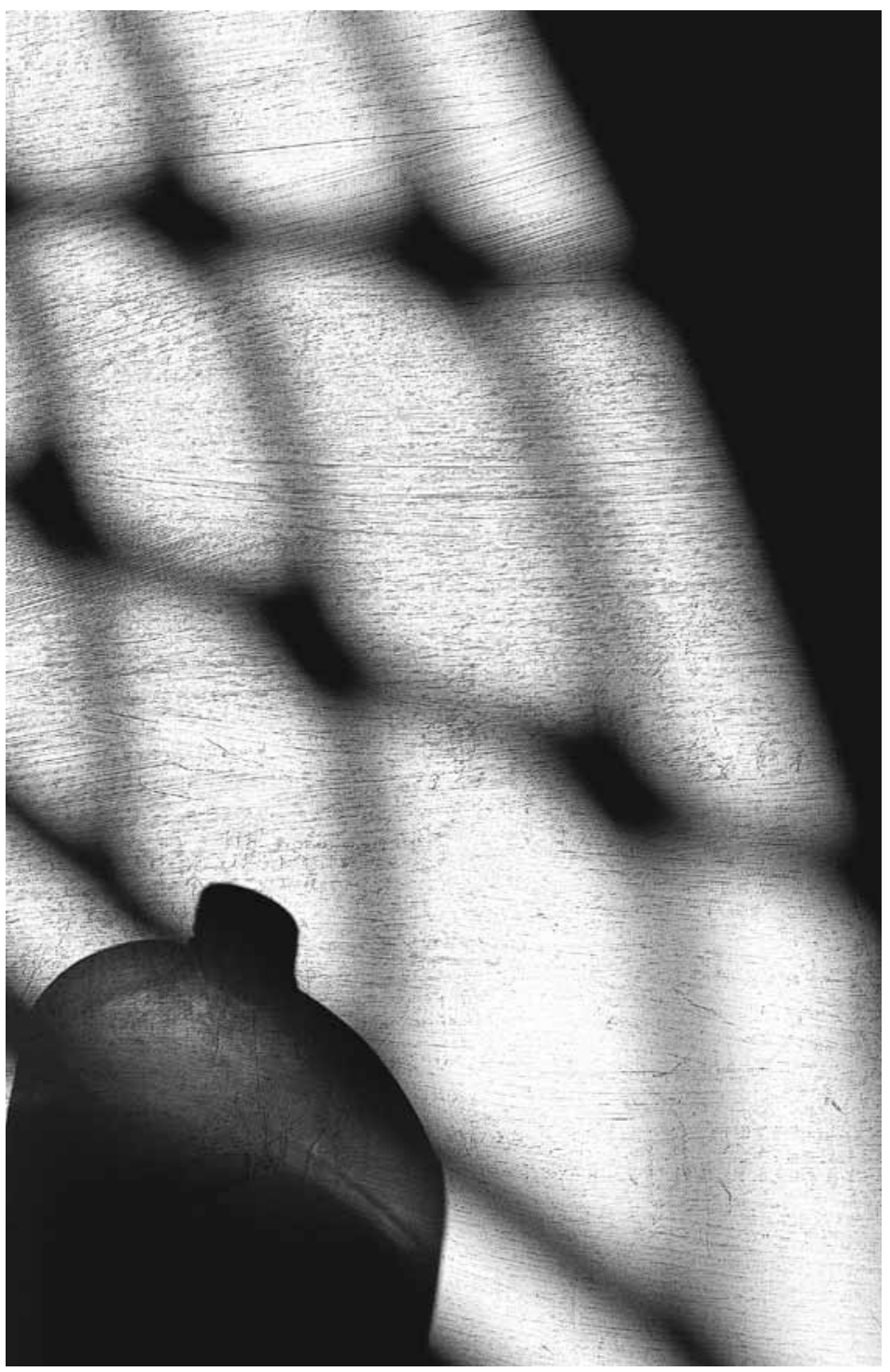


Essa imagem assume de primeira mão um caráter abstrato, devido ao enquadramento fechado e à incerteza dos motivos. Um recorte reduzido, isolado, do entorno, mostra a proeminência de linhas orgânicas em uma estrutura compositiva completamente atípica, onde cada elemento atua com força individual dentro do quadro. A foto direta, captada na fugacidade de um instante, recria um ambiente tomado pela sombra, mas efusivamente iluminado pela luz intrusa do Sol na hora do levante.

O espaço em claro, coberto por uma sutil textura visual, tendendo a tátil, se impõe no escuro, deixando indícios de vigor sobre a superfície largamente envelhecida. Um conjunto de módulos capsulares organizados em faixas e colados entre si descem nesse espaço, se multiplicando, com ritmo visual geométrico e progressivo. Ali embaixo surge um volume expectante, intrometido, irrompendo o ritual de claro-escuro, não pertencente à cerimônia porque leva um enfeite colorido no corpo avultado de penumbra, mas fica aceito finalmente pelo gosto tentador da anomalia.

A cena foi 'congelada' dentro dos vãos da arcada de acesso ao convento de São Francisco; nesse hall meio escuro, rodeado de grossas paredes brancas de taipa, onde há um guichê de atendimento ao público e uma pequena loja de artesanato religioso. Expectantes por entrar, algumas pessoas aguardam sentadas em uma antiga bancada de madeira encostada à parede; nem todos são turistas querendo conhecer o complexo arquitetônico, há também fiéis que procuram serviços vários ou anseiam confessar-se com os padres franciscanos na intimidade dos claustros.

Dois elementos da realidade visível, um palpável e outro intangível, coexistem à vontade no formato vertical da foto: emergindo abaixo, no primeiro plano, a parte superior de uma garrafa de material plástico cor verde; e ocupando quase por completo o plano de fundo, a sombra (projetada na parede do hall) da grade, em forma de abanico, que cobre o arco de um dos vãos da arcada. A garrafa, espacialmente falando, não toma posse nem de uma quarta parte do enquadramento, no entanto se destaca, por ser responsável pelo detalhe colorido da imagem e porque a projeção da sombra desenha sobre a superfície iluminada do fundo essas faixas fragmentadas de luz, que parecem assinalar a garrafa, conduzindo o olhar do observador até ela. 
Desprendendo-se em contraluz do plano de fundo, a garrafa ganha mais presença em razão de sua proximidade com a câmera. Tanto a garrafa quanto as faixas luminosas aparecem imponentes pelo ângulo de tomada de baixo para cima, as duas dialogam entre si, assinalando-se mutuamente, em um jogo de vai e volta. Também o ponto de focalização se concentra no lombo enverdecido da garrafa, porém o plano atrás dela, que na verdade não está tão distante, aparece desfocado, revelando o uso de pouca profundidade de campo.

Ficam, desse modo, estabelecidos dois centros de interesse: um deles, ocupando o maior espaço no enquadramento, é a sombra da grade em leque no plano de fundo, mas, curiosamente, esse plano precisamente não está dado à visão, a imagem figurativa da projeção da sombra é quase desintegrada através do desfoque, enquanto o foco vai para o primeiro plano revelando a textura cromática da garrafa. Acontece, dessa forma, uma "inversão das expectativas figurativas", como diria Machado, na relação da zona de nitidez com o objeto fotografado. De acordo com ele (1984, p. 19): "é preciso que a intenção do olho enunciador contradiga a hierarquia da cena e subverta a ordem que dita o arranjo do motivo para que o foco possa aparecer como fissura". Nesse sentido, embora diluída em uma mancha amorfa, a sombra não deixa de ser percebida; essa grande zona desfocada não interfere na transmissão de sentido na fotografia, ao contrário, o promove, é a marca visível da existência fugaz de um objeto ausente, indica a fragilidade e volubilidade da vida.

O outro centro de interesse é a garrafa, mas que sentido teria fotografar uma garrafa de matéria plástica? Não é por acaso que esse recipiente vazio está naquele lugar, nem por acaso que foi incluído na composição, é um objeto utilitário -preferentemente de reciclagem - empregado por inúmeros crentes, para receber nele uma boa quantidade de água benta que emana de uma pia batismal no interior do convento. $\mathrm{O}$ líquido de vida espiritual, recolhido todo dia para uso doméstico, é untado nas pessoas que precisam sarar ou requerem purificação e representa, para grande parte da população equatoriana, um forte símbolo de esperança e de fé católica.

Chegado nesse ponto da análise da efemeridade da sombra através da imagem fotográfica, estamos em condições de identificar duas instâncias que tem dirigido, neste estudo, nossa compreensão do problema: a primeira é o evento, o momento em que tudo ocorre, no cenário real, no campo de ação. Naquela instância, a 
sombra é um efeito efêmero, imaterial, que pertence ao mundo do impalpável. Ao mesmo tempo, nessa primeira instancia intervêm quatro componentes essenciais, sem os quais simplesmente nada poderia acontecer: luz, objeto, plano e projeção. Eles cumprem papéis diferenciados e até contrários aos que respondem tradicionalmente. A luz importa na sua condição de luz incidente como fundo; o objeto interessa como obstáculo; o plano atua como suporte e a projeção como figura.

A segunda instância é o resultado da captação do evento, a foto impressa ou visualizada na tela do computador, a imagem materializada na proposta. Aqui a sombra passa do efêmero a o eterno, cobrando vida continuamente como parte dos elementos compositivos da imagem. Nessa alçada está implícita a intervenção do fotógrafo-artista como ente mediador entre a câmera e o evento, sem o qual o resultado não seria possível. Os componentes, que na primeira instância são utilitários, nessa segunda adquirem um caráter interpretativo, se desprendendo, às vezes, da sua própria natureza. A luz atua como transparência, o objeto como símbolo, o plano como modelador e a projeção como ficção. Porém, dessa vez, "a realidade está nas imagens, não no mundo concreto, pois este é efêmero e aquela, perpétua. A realidade das imagens é a realidade da sombra, sem carne, sem sangue..." (KOSSOY, 2007, p. 142).

Meu trabalho com as sombras tenta explorar novos rumos, se aproximando bem do conceito de fotografia criadora ${ }^{5}$, que, de acordo com André Rouillé, é uma versão da arte fotográfica, perfeitamente delimitada. Rouillé conduz a sombra no caminho da arte; outorga-lhe uma capacidade diferenciada para expressar uma ideia que vai muito além do "registro" (como característica da fotografia utilitária de uso comercial ou familiar), sem que para isso tenha sido necessário construir nada virtualmente. Nesse sentido, a pesquisa deixa entrever a predileção do autor pelo uso da fotografia direta, se ajustando também com os postulados dessa versão da arte fotográfica, já que: "a fotografia criadora caracteriza-se pelo respeito à pureza do procedimento e pelo seu papel de redentora da arte contemporânea" (ROUILLÉ, 2009, p. 278). Em virtude dessa experiência prática e teórica, eu acrescentaria no mesmo conceito o reflexo e, ainda, o poder do efêmero, para estabelecer a construção de novos mundos visuais na base dos existentes. Fecho, desse modo, ao menos provisoriamente, o telão onde foram desvendados alguns segredos visíveis, nesse caso da cidade de Quito. Há muito ainda por descobrir, muitas cidades patrimoniais para percorrer, infinitas sombras e luzes por capturar...
5. Em um contexto radicalmente diferente, o da França dos anos 1970, um amplo movimento cultural a favor da fotografia acelera o nascimento de uma nova versão da arte fotográfica, que será designada por um termo proveniente de Jean-Claude Lemagny: a "fotografia criadora" (ROUILLE, 2009, p. 275). 
6. Frase extraída em aula de Teoria da Imagem e da Cultura Visual ministrada pelo professor Dr. Raimundo Martins no dia 14 de abril de 2008.

\section{Conclusões:}

A respeito da própria obra cremos, através deste trabalho, entre outras coisas, ter exteriorizado nossa convicção de reivindicar a fotografia artística direta, como opção autêntica e nobre da arte fotográfica contemporânea, mas não para honrar as práticas do passado, pelo contrário, para situarmos consciente e criadoramente no presente.

Eis o desafio de adotar intencionalmente uma função dupla: nas condições do presente trabalho o autor teve que converter-se no espectador da própria obra, desdobrar-se entre produtor e critico, entre gerador e receptor. Contudo hoje, rematando nas conclusões, tenho minhas dúvidas de se cheguei mesmo a exercer um ato de autointerpretação, mas o que eu fiz com certeza, foi tentar dar um sentido a minha obra, um significado inteligível. Vou deixar para o leitor a tarefa da sua própria interpretação, finalmente tenho a plena consciência de que a partir da imagem se desprender da sua origem, nós não temos mais controle sobre ela ${ }^{6}$.

Talvez este texto tenha um "ar" um tanto diferenciado dos que estamos acostumados a ler, é que há muito sobre fotografia escrito por filósofos, antropólogos, sociólogos, comunicadores sociais, críticos de arte, professores de arte, etc. e tão pouco por fotógrafos. Tomara que (mesmo com as limitações idiomáticas em minha condição de estrangeiro), este seja mais um estímulo para centos de fotógrafos-artistas que precisam teorizar o seu trabalho e mais um texto que faça justiça à visão fotográfica.

\section{Referências Bibliográficas:}

AUMONT, Jacques. A Imagem. Campinas, SP: Papirus, 1993.

BARTHES, Roland. A câmara clara: nota sobre a fotografia, $9^{\mathrm{a}} \mathrm{Im}-$ pressão. Rio de Janeiro: Nova Fronteira, 1984.

BENJAMIN, Walter. Magia e técnica, arte e política: ensaios sobre literatura e história da cultura. São Paulo: Brasiliense, 1994.

BRASSAÏ. Paris after dark. London: Thames and Hudson, 1987.

CALVINO, Italo. As cidades invisíveis. São Paulo: Companhia das Letras, 1990. 
CARTIER-BRESSON, Henri. Fotografiar del Natural. Barcelona: Gustavo Gili, 2003.

CERTEAU, Michel de. A invenção do cotidiano: 1 artes de fazer. $11^{\mathrm{a}}$ Ed. Petrópolis, RJ: Vozes, 1994.

FERNANDES JÚNIOR, Rubens. Labirinto e Identidades: panorama da fotografia no Brasil [1946 - 1998]. São Paulo: Cosac \& Naify, 2003.

FLUSSER, Vilém. Filosofia da caixa preta: ensaios para uma futura filosofia da fotografia. São Paulo: Editora Hucitec, 1985.

GAUTRAND, Jean-Claude. Brassaï, o Universal. Italy: TASCHEN, 2004.

GREEN, David. (Ed.) Qué há sido de La fotografia. Barcelona: Gustavo Gili, 2007.

JOLY, Martine. Introdução a analise da imagem. Campinas,SP: Papirus, 1996.

KOSSOY, Boris. Os tempos da fotografia: o efêmero e o perpétuo. Cotia, SP: Ateliê Editorial, 2007.

LANGFORD, Michael. Enciclopédia Completa de Fotografia. Madrid: Hermann Blume Ediciones, 1983, p.328-382.

LUZURIAGA, Camilo. Paisajes y "Paisajes". Catálogo da exposição. Ibarra, Equador abril 2003.

MACHADO, Arlindo. A Fotografia como Expressão do Conceito. Revista Studium Vol. 2, p.1-18 inverno 2000 In: http://www.studium. iar.unicamp.br/ dois/index.htm, acessado 10/o9/2007

MACHADO, Arlindo. A Ilusão Especular: introdução à fotografia. São Paulo: Editora Brasiliense, 1984.

MAKOWIECKY, Sandra. A iconografia urbana e os espaços cênicos da memória da cidade. Visualidades: Revista do Programa de mestrado em Cultura Visual, Goiânia GO, Vol. 5 n. 2, p.32-63, Jul - Dez/2007. 
MARCHÁN FIZ, Simón. Contaminaciones figurativas. Madrid: Alianza Forma, 1986.

MOLINA, Sebastián. Quito: toca el cielo. Corporación Metropolitana de Turismo, Quito: Imprenta Mariscal, 2002.

MONTANER, Josep María. As formas do século XX. Barcelona: Gustavo Gili, 2002.

MOYA, Rómulo. El Quito de los Charcos...el momento y su eternidad. Catálogo da exposição. Quito, Equador outubro 2005.

PEIXOTO, Nelson Brissac. Paisagens Urbanas. 2º Edição. São Paulo: Editora SENAC, 1998.

ROUILLÉ, André. A fotografia: entre documento e arte contemporânea. São Paulo: Editora SENAC, 2009.

SAMAIN, Etienne. O Fotográfico. 2oㅡㄹ Eção. São Paulo: Editora SENAC, 2005. 350p.

SONTAG, Susan. Sobre fotografia. São Paulo: Companhia das Letras, 2004.

VASCONCELOS Milke, Cláudia. Foto Clube do Espírito Santo: A arte fotográfica numa trajetória específica. Dissertação de Mestrado. Vitória, 2008.

VASCONCELlOS, Cássio. Noturnos. São Paulo: Bookmark, 2002.

VIGANÒ, Enrica. FRANCO FONTANA, Territórios Confrontados. Catálogo da Exposição. Albacete, Espanha, maio de 2005. 


\section{RAÚL YÉPEZ COLLANTES [YEPO]}

É arquiteto pela Universidade Central do Equador FAU-UC, professor da Faculdade de Arquitetura, Design e Artes da Pontifícia Universidade Católica do Equador PUCE. Mestr e em Cultura Visual pela Faculdade de Artes Visuais da Universidade Federal de Goiás. FAV-UFG. Artista pesquisador no campo da fotografia. Web site: www.yepo-photo.com.

Email:yepo@yepo-photo.com 